\title{
Influence of Psychosocial Factors on Energy Drink Consumption in Korean Nursing Students: Never-consumers versus Ever-consumers
}

\author{
Jihea Choi \\ Assistant Professor, Department of Nursing, Yonsei University Wonju College of Medicine, Wonju, Korea
}

Purpose: This study aimed to investigate the status of caffeine-containing energy drink consumption among Korean nursing students and to identify associated psychological factors. Methods: In total, 187 Korean nursing students participated in this cross-sectional study. A self-administered questionnaire was used to identify participants' general characteristics and psychosocial factors (self-esteem, academic stress, depression, and college adjustment) associated with energy drink consumption. Data were analyzed with SPSS using descriptive statistics, the $x^{2}$ test, the t-test, and logistic regression. Results: More than two-thirds (73.3\%) of the participants had consumed energy drinks. Among the investigated psychological factors, depression appeared to most strongly influence energy drink consumption behaviors in this population. Conclusion: The consumption of caffeine-containing energy drinks was found to be common among nursing students preparing to become health care professionals; depressed nursing students were more likely to have consumed energy drinks than non-depressed students. Nursing educators should emphasize the early detection of unhealthy beverage consumption habits and provide appropriate education to enhance healthy behaviors in future health care professionals.

Key words: Energy drinks; Nursing student; Depression

\section{Corresponding author Jihea Choi}

https://orcid.org/0000-0003-1881-6342

Department of Nursing, Yonsei University Wonju College of Medicine, 20 Ilsan-ro, Wonju 26426, Korea

TEL +82-33-741-0379 FAX +82-33-743-9490

E-MAIL jiheachoi@yonsei.ac.kr

Received Oct 29, 2018 Revised Dec 10, 2018 Accepted Dec 19, 2018 (a) This is an Open Access article distributed under the terms of the Creative Commons Attribution NonCommercial License (http://creativecommons.org/licenses/by-nc/4.0/) which permits unrestricted noncommercial use, distribution, and reproduction in any medium, provided the original work is properly cited.

\section{INTRODUCTION}

The energy drink known as Red Bull ${ }^{\mathrm{TM}}$ was introduced to the public in Austria in 1987, North America in 1997, and South Korea in 2011. The popularity of energy drinks has increased among young individuals through aggressive slogans in marketing campaigns. These drinks are advertised as being able to enhance energy, alertness, concentration, and athletic performance [1,2]. This marketing strategy has also been successful in Korea. According to a Korean news report, the Korean energy drink market tripled between 2012 and 2013 [3] and has steadily increased up to the present [4]. One reason for the high level of energy drink consumption among Korean adults is the need for additional energy during long academic or working hours [5]. For many college students, academic stress related to future employment triggers a feeling of pressure to achieve a high grade point average, causing psychological stress that leads college students to stay awake for long periods of time [5,6]. In the 1980s and 1990s, a stimulant called "Timing" (with $50 \mathrm{mg}$ of caffeine per tablet; standard dose: 2 tablets) became popular among teenagers and young people in Korea who needed more energy to stay alert over long study and work hours [5]. However, energy drinks are now widespread as a stronger next-generation stimulant in Korea. 
Energy drinks contain large doses of caffeine and other legal stimulant and non-stimulant ingredients, including taurine, guarana, sucrose, glucose, glucuronolactone, inositol, niacin, panthenol, and vitamins [1]. However, the ingredient that causes the most concern is caffeine, which can be present at a level as high as $505 \mathrm{mg} /$ serving; this is much higher than levels found in soda (35 50 mg caffeine/ serving) and coffee (77 $150 \mathrm{mg}$ caffeine/serving) [7]. Consumption of large amounts of caffeine, a central nervous system stimulant, can lead to acute caffeine intoxication [8]. Symptoms of caffeine intoxication may include adverse cardiovascular (e.g., arrhythmias, tachycardia, hypertension, and coronary vasospasms) and neurological effects (e.g., seizures, agitation, aggressive behavior, and suicidal ideation) [1]. In spite of its potential dangers, energy drink consumption among young Korean adults and teenagers is a remarkable social phenomenon [3-5]. Therefore, it is important to identify patterns of energy drink consumption in young Korean people, as well as factors that affect consumption, to prevent the adverse effects associated with long-term consumption of highly-caffeinated energy drinks.

There is growing interest in associations between caffeine and psychological conditions, such as stress, anxiety, depression, and suicidal ideation, among young people $[9,10]$. Many studies have found positive associations between energy drink consumption and stress, anxiety, and depression, confirming that these behaviors are closely linked [9]. Well-being is a particularly important parameter to assess, because it serves as an indicator of how well students have adjusted to college life. Furthermore, self-esteem reflects an individual's overall emotional appraisal of his or her self-worth, and is a major factor associated with substance or stimulant use-including energy drinks combined with alcohol-among young people. Self-esteem affects an individual's assessments of his or her competence, importance, and health-related behaviors. However, many people who rely on substances have low self-esteem and are more likely to become reliant on such substances in adolescence or young adulthood [11]. Those psychological characteristics affect students' adjustment to college, specifically the ease with which students achieve a harmonious state, without encountering conflicts or perceiving imbalances [12]. Given the widespread use of caffeine-containing energy drinks, their potential harmful effects on academic performance and personal adjustment are similarly broad in scope [13]. Therefore, there is a need to confirm the associations of self-esteem, academic stress, depression, and college adjustment with energy drink consumption.

Many Korean studies have examined energy drink consumption among young Korean people, especially college students $[14,15]$. Most studies have focused on identifying the demographic factors that affect energy drink consumption, and only a few have identified psychosocial factors affecting energy drink consumption [16]. Young adulthood is an important time when lifestyle habits are established and fixed across a lifetime. In addition, college is a unique environment where students can develop health-related behaviors [17]. Nursing schools train students with the knowledge and skills necessary to attain, maintain, or recover optimal health and quality of life for individuals, families, and communities. Moreover, nursing students become health professionals after graduation, and it is therefore imperative that they cultivate behaviors that will positively impact their own health, in addition to the health of the patients they will serve [17]. Health care professionals seek to influence or improve health status by preventing or ameliorating risky health behaviors through health education or role modeling [18]. These expectations are particularly applicable to nurses, who care for patients directly at the bedside [17]. Therefore, investigating the risky health behaviors of nursing students, including energy drink consumption, which has recently increased among young people despite the high caffeine content of these drinks, is imperative.

The author investigated energy drink consumption among Korean nursing students and attempted to identify psychological factors that influenced consumption. The specific study purposes were as follows: (1) to investigate the status of energy drink consumption and associated psychosocial variables (self-esteem, academic stress, depression, and college adjustment) among Korean nursing students; and (2) to identify how the associated psychosocial factors influenced energy drink consumption among Korean nursing students. Such information would be helpful for formulating early intervention programs that promote the development of health habits among nursing students. In addition, the results of this study may be used to establish health behavior interventions for 3 -shift health care workers, specifically nurses.

\section{METHODS}

\section{Research Design}

The author used an exploratory cross-sectional descriptive study design to identify psychosocial factors associated with energy drink consumption among Korean nursing students.

\section{Participants and Data Collection}

The target population included all nursing students, from freshman to seniors, attending a nursing university in an urban Korean city. From May to July 2014, 200 survey ques- 
tionnaires were distributed (50 students per year-level), corresponding to the total number of nursing students enrolled at the participating nursing university. Only participants who signed a consent form participated in this study. Sufficient time (15 20 minutes) was provided to complete the questionnaire, which was then returned in an unmarked envelope to preserve respondents' anonymity. Ultimately, 187 nursing students participated in this study.

\section{Instruments}

A self-administered questionnaire was used to identify participants' energy drink consumption, general characteristics (sex, school year, residence, cigarette smoking, alcohol consumption, self-health interest, and self-health management), and psychosocial factors (self-esteem, academic stress, depression, and college adjustment). Items on the general characteristics questionnaire that were deemed likely to be answered with a median score were constructed with answers on a dichotomous scale (e.g. yes or no).

\section{1) Energy drink consumption}

The author defined energy drinks as beverages containing high concentrations of caffeine, including Red Bull ${ }^{\mathrm{TM}}$, Bac$\operatorname{chus}^{\mathrm{TM}}$, Hot $6^{\mathrm{TM}}$, Monster ${ }^{\mathrm{TM}}$, Burn Intense ${ }^{\mathrm{TM}}$, and Rock Star ${ }^{\mathrm{TM}}$. As a measure of the status of energy drink consumption, the author determined whether participants had ever consumed energy drinks. Those who had never consumed energy drinks were classified as never-consumers, and those who had consumed energy drinks at least once in their life were classified as ever-consumers.

\section{2) Self-esteem}

Self-esteem reflects an individual's overall emotional evaluation of worth. It was assessed using Rosenberg's SelfEsteem Scale [19], which was translated to Korean and used in Ryu's study [20]. The instrument consists of 10 questions that use a 4-point Likert scale ranging from "strongly disagree (1)" to "strongly agree (4)". Individual scores were summed to form a total score, which was then converted to a 100-point scale; potential total scores ranged from 25 to 100 . The author then converted the total mean score to an item mean to facilitate comparisons with other study variables. High scores correspond to high levels of self-esteem. In terms of reliability, the questionnaire had a Cronbach's $\alpha$ of .85 .

\section{3) Academic stress}

Academic stress refers to the perceived overall stress level during college life. It was measured using one question: "What is your stress level, related to your academic experi- ence, while attending nursing college?" The answers to the question were evaluated on a 4-point Likert scale ranging from "very low (1)" to "very high (4)".

\section{4) Depression}

Depression is a state of low mood and aversion to activity that can affect an individual's thoughts, behaviors, feelings, and sense of well-being. The author measured depression using the Beck Depression Inventory (BDI) [21], which has been translated into Korean [22]. The instrument consists of 21 questions, assessed along a 4-point Likert scale ranging from "not present (0)" to "severe (3)". The total score ranges from 0 to 63 , with higher scores indicating more severe depressive symptoms. A BDI cutoff score of 17 is used to determine the presence of depression [21]; those scoring $\leq 16$ points were considered not to have depression and those scoring $\geq 17$ points were considered to have depression. To facilitate a comparison of the mean score with other study variables, the author converted the sum mean score into item mean scores. In terms of reliability, the questionnaire had a Cronbach's $\alpha$ of .83 in this study.

\section{5) College adjustment}

College adjustment refers to the ability of university students to maintain a harmonious state, without encountering conflicts and imbalances, by coping with academic, interpersonal, and emotional college life needs. It was measured using Baker and Siryk's Student Adaptation to College Questionnaire [23], which was used in a previous Korean study [24]. The instrument consists of 67 questions that use a 5-point Likert scale ranging from "strongly disagree (1)" to "strongly agree (5)". The total score ranges from 67 to 335 . The author converted the sum mean score to item mean scores, with higher scores indicating appropriate adjustment to college life. In terms of reliability, the questionnaire had a Cronbach's $\alpha$ of .84 in this study.

\section{Data Analysis}

Statistical tests were used to evaluate all collected data using SPSS for Windows version 20.0 (IBM Corp., Armonk, NY, USA), at a significance level of $.05(p<.050)$. Descriptive statistics were used to characterize the study population. Differences in general characteristics and study variables related to energy drink consumption were analyzed using the $x^{2}$ test and the t-test. Lastly, logistic regression was used to identify the psychosocial factors influencing energy drink consumption behavior among Korean nursing students.

\section{Ethical Considerations}


This study was approved by the Research Ethics Committee of the authors' affiliated university (Institutional Review Board number: YWNR-14-2-027). Participants were informed about the study's purpose and intent, data confidentiality and anonymity, and their right to withdraw from study participation at any time. Written informed consent was obtained from all participants prior to study initiation.

\section{RESULTS}

\section{General Characteristics of Participants}

There were 187 nursing students who completed and returned the survey (93.5\% response rate). Among the participants, $82.4 \%$ were females and $17.6 \%$ were males. The distributions of the participants by year in school ranged from $19.8 \%-27.3 \%$ from freshmen to seniors. Only $10.2 \%$ of participants lived with their families, $86.1 \%$ were non-smokers, and $74.9 \%$ were alcohol consumers. And, $79.1 \%$ of participants reported not being interested in their own health, yet $49.2 \%$ felt that they were managing their health well. The only statistically significant difference between energy drink never-consumers and ever-consumers was alcohol consumption, with consumers exhibiting significantly higher alcohol consumption $\left(x^{2}=6.00, p<.021\right)$ (Table 1$)$.

\section{Status of Energy Drink Consumption}

Among 187 nursing college students, 50 (26.7\%) were never-consumers, while 137 (73.3\%) were ever-consumers. More than two-thirds of nursing college students had consumed energy drinks in their life.

\section{Psychosocial Variables Influencing Energy Drink Consumption}

The item mean score of variables that influenced energy drink consumption are shown in Table 2 . The item mean score of self-esteem was 1.92 of 4 , that for academic stress was 2.64 of 4 , that for depression was 0.41 of 3 , and that for college adjustment was 3.17 of 5 . Among psychological variables, academic stress ( $\mathrm{t}=2.51, p=.013)$, depression $(\mathrm{t}=2.91, p=.004)$, and college adjustment $(\mathrm{t}=3.84, p<.001)$ were significantly different between never-consumers and ever-consumers.

\section{Psychosocial Factors Influencing Energy Drink Consumption}

Table 3 presents the final logistic regression model for energy drink consumption based on psychological factors in Korean nursing students (never-consumers and ever-consumers). Model 1 shows the association between alcohol and

Table 1. General Characteristics of Study Participants

$(N=187)$

\begin{tabular}{|c|c|c|c|c|c|}
\hline \multirow[t]{2}{*}{ Variables } & \multirow[t]{2}{*}{ Categories } & $\begin{array}{c}\text { Total } \\
(\mathrm{n}=187)\end{array}$ & $\begin{array}{l}\text { Never-consumers } \\
(n=50)\end{array}$ & $\begin{array}{c}\text { Ever-consumers } \\
(\mathrm{n}=137)\end{array}$ & \multirow[t]{2}{*}{$x^{2}(p)$} \\
\hline & & $\mathrm{n}(\%)$ & $\mathrm{n}(\%)$ & $\mathrm{n}(\%)$ & \\
\hline \multirow[t]{2}{*}{ Sex } & Female & $154(82.4)$ & $44(88.0)$ & $110(80.3)$ & \multirow[t]{2}{*}{$1.50(.281)$} \\
\hline & Male & 33 (17.6) & $6(12.0)$ & 27 (19.7) & \\
\hline \multirow[t]{4}{*}{ School year } & Freshman & 49 (26.2) & $15(30.0)$ & $34(24.8)$ & \multirow[t]{4}{*}{$3.22(.359)$} \\
\hline & Sophomore & $50(26.7)$ & $12(24.0)$ & $38(27.8)$ & \\
\hline & Junior & 37 (19.8) & $13(26.0)$ & 24 (17.5) & \\
\hline & Senior & $51(27.3)$ & $10(20.0)$ & 41 (29.9) & \\
\hline \multirow[t]{2}{*}{ Residence } & With family & $19(10.2)$ & $6(12.0)$ & $13(9.5)$ & \multirow[t]{2}{*}{$0.25(.593)$} \\
\hline & Without family & $168(89.8)$ & $44(88.0)$ & $124(90.5)$ & \\
\hline \multirow[t]{2}{*}{ Cigarette smoking } & Nonsmoker & $161(86.1)$ & $43(86.0)$ & $118(86.1)$ & \multirow[t]{2}{*}{$0.01(.575)$} \\
\hline & Smoker & $26(13.9)$ & $7(14.0)$ & 19 (13.9) & \\
\hline \multirow{2}{*}{$\begin{array}{l}\text { Alcohol } \\
\text { consumption }\end{array}$} & Nondrinker & 47 (25.1) & $19(38.0)$ & $28(20.4)$ & \multirow[t]{2}{*}{$6.00(.021)$} \\
\hline & Drinker & $140(74.9)$ & $31(62.0)$ & $109(79.6)$ & \\
\hline \multirow{2}{*}{$\begin{array}{l}\text { Interest in one's } \\
\text { own health }\end{array}$} & Interested & 39 (20.9) & $9(18.0)$ & 30 (21.9) & \multirow[t]{2}{*}{$0.34(.685)$} \\
\hline & Not interested & $148(79.1)$ & $41(82.0)$ & $107(78.1)$ & \\
\hline \multirow{2}{*}{$\begin{array}{l}\text { Management of } \\
\text { one's own health }\end{array}$} & Good & $92(49.2)$ & $30(60.0)$ & $62(45.3)$ & \multirow[t]{2}{*}{$3.19(.098)$} \\
\hline & Poor & $95(50.8)$ & $20(40.0)$ & 75 (54.7) & \\
\hline
\end{tabular}


Table 2. Psychosocial Variables of Study Participants

$(N=187)$

\begin{tabular}{|c|c|c|c|c|}
\hline \multirow{2}{*}{ Variables (item range) } & Total $(\mathrm{n}=187)$ & Never-consumers $(n=50)$ & Ever-consumers $(\mathrm{n}=137)$ & \multirow{2}{*}{$\mathrm{t}(p)$} \\
\hline & $\mathrm{M} \pm \mathrm{SD}$ & $\mathrm{M} \pm \mathrm{SD}$ & $\mathrm{M} \pm \mathrm{SD}$ & \\
\hline Self-esteem $(1 \sim 4)$ & $1.92 \pm 0.32$ & $1.99 \pm 0.34$ & $1.89 \pm 0.31$ & $1.89(.061)$ \\
\hline Academic stress (1 4) & $2.64 \pm 0.63$ & $2.46 \pm 0.68$ & $2.72 \pm 0.59$ & $2.51(.013)$ \\
\hline Depression $(0 \sim 3)$ & $0.41 \pm 0.32$ & $0.31 \pm 0.27$ & $0.45 \pm 0.33$ & $2.91(.004)$ \\
\hline College adjustment $(1 \sim 5)$ & $3.17 \pm 0.29$ & $3.29 \pm 0.21$ & $3.13 \pm 0.30$ & $3.84(<.001)$ \\
\hline
\end{tabular}

Table 3. Psychosocial Factors Influencing Energy Drink Consumption

$(N=187)$

\begin{tabular}{|c|c|c|c|c|c|c|c|c|c|c|}
\hline \multirow{2}{*}{ Characteristics } & \multicolumn{5}{|c|}{ Model 1} & \multicolumn{5}{|c|}{ Model 2} \\
\hline & $\beta$ & SE & $p$ & OR & $95 \% \mathrm{CI}$ & $\beta$ & SE & $p$ & OR & $95 \% \mathrm{CI}$ \\
\hline (Constant) & 0.39 & .30 & .192 & & & 2.44 & 2.71 & .374 & & \\
\hline Alcohol consumption (nondrinker $=0$, drinker $=1$ ) & 0.87 & .36 & .016 & 2.39 & $1.18 \sim 4.83$ & 0.80 & 0.39 & .041 & 2.22 & $1.03 \sim 4.79$ \\
\hline Self-esteem & & & & & & 0.32 & 0.69 & .641 & 1.38 & $0.36 \sim 5.36$ \\
\hline Academic stress & & & & & & 0.35 & 0.31 & .261 & 1.42 & $0.77 \sim 2.61$ \\
\hline Depression $\left(\right.$ no $^{*}=0$, yes $\left.^{\dagger}=1\right)$ & & & & & & 1.60 & 0.62 & .010 & 4.94 & $1.46 \sim 16.70$ \\
\hline \multirow[t]{2}{*}{ College adjustment } & & & & & & -1.19 & 0.69 & .085 & 0.30 & $0.08 \sim 1.18$ \\
\hline & \multicolumn{5}{|c|}{ Nagelkerke $R^{2}=.044(p=.017)$} & \multicolumn{5}{|c|}{ Nagelkerke $R^{2}=.190(p<.001)$} \\
\hline
\end{tabular}

${ }^{*} \mathrm{No}=\leq 16$ Points; ${ }^{\dagger} \mathrm{Yes}=\geq 17$ points; $\mathrm{OR}=$ Odds ratio; $\mathrm{CI}=$ Confidence interval; $\mathrm{SE}=$ Standard error.

energy drink consumption among nursing students (Nagelkerke $\mathrm{R}^{2}=.044, p=.017$ ). Model 2 shows the associations between various psychological factors and energy drink consumption among college students who consumed alcohol (Nagelkerke $\mathrm{R}^{2}=.190, p<.001$ ). Of the psychosocial variables we assessed (self-esteem, academic stress, depression, and college adjustment), only depression significantly influenced energy drink consumption. Depressed nursing students were 4.9 times more likely to have consumed energy drinks than non-depressed nursing students (odds ratio=4.94, $p=.010$ ). The Hosmer-Lemeshow test revealed a $p$ value of .914, indicating good model fit because the $p$ value was $>.05$. Moreover, the classification results were moderate, with $74.3 \%$ correct model classification.

\section{DISCUSSION}

For many young people, college marks the transition from adolescence to adulthood. Therefore, college is a very important time during which healthy dietary habits are established. Prior studies have indicated that college students have poorquality diets that fail to meet recommended national dietary standards [8,25]. A similar pattern has been observed among Korean college students, although college students who express awareness of the potential side effects of energy drink consumption still demonstrate high levels of consumption [15]. Of the nursing college students who participated in this study, more than two-thirds $(73.3 \%)$ had consumed energy drinks. These results are similar to other findings on the level of energy drink consumption among Korean nursing college students $(78.1 \%)$, an age group with high levels of energy drink consumption [14]. A Canadian study found that $73.6 \%$ of young individuals had reportedly consumed energy drinks [26] and $77.3 \%$ of college students consumed energy drinks at least once per week [8]. Thus, attention to health issues related to high levels of energy drink consumption is important.

There are known positive associations between mental health problems, such as stress and depression, and energy drink consumption [9]. Similarly, among the psychological factors in this study, depression significantly influenced energy drink consumption in this population. Depressed nursing students were 4.94 times more likely to have consumed energy drinks than those who were not depressed. This result provides evidence that nursing students who are heavy energy drink consumers may need to evaluate their own psychological condition, considering possibilities such as a depressed mood. This finding also suggests that energy drink consumption is not simply an unhealthy eating habit related to beverage preferences. Nursing students are expected to be role models for the general population, promoting healthy 
lifestyles and mental health [17]. Therefore, nursing educators should be aware of the seriousness of mental health problems associated with energy drink consumption in this population. Moreover, nursing educators should emphasize the early detection of unhealthy beverage consumption habits in individuals with depression and provide interventions to rebuild healthy habits and promote mental health. These efforts may help nursing students to grow into nurses who promote healthy beverage consumption behavior in the patients they serve and in the community at large in the near future.

Prior research has identified sociodemographic factors that influence energy drink consumption among college students. These include sex, alcohol consumption, smoking, monthly income, and residing in urban areas $[1,25,27]$. In this study, alcohol consumption was the only sociodemographic factor that significantly differed between nursing students who never consumed energy drinks and those who had; furthermore, the alcohol consumption rate among ever-consumers was relatively high. This finding reinforces the close association between alcohol and energy drink consumption. Moreover, consuming alcohol in combination with energy drinks is a popular trend among young people $[28,29]$, especially in light of the finding that drinking alcohol combined with energy drinks makes the drinker feel like he or she is drinking more slowly [28]. Thus, this combination promotes overconsumption of alcohol and is a risky health behavior [29], and future research should therefore investigate the practice of mixing energy drinks and alcohol.

The author intensively explored self-esteem, academic stress, depression, and college adjustment as psychological factors that could affect energy drink consumption in college students, based on previous studies $[1,10,13]$. Even though depression was the only variable significantly related to energy drink consumption in the final regression model, other psychological factors (academic stress and college adjustment, including depression) significantly differed between never-consumers and ever-consumers in a difference comparison analysis. Ever-consumers showed higher academic stress and depression and lower college adjustment scores than never-consumers. Based on a previous study, caffeine is the most commonly-used psychoactive substance [13]; moreover, it influences undesirable mental health problems [9]. Similarly, Hofmeister et al. [30] and Trapp et al. [10] identified relationships between energy drink consumption behaviors and stress. Richards and Smith [9] and Trapp et al. [10] have also identified correlations between total energy drink consumption and depression scores among young people. This may confirm that depression was the most important psychological factor influencing nursing students' consumption of energy drinks. Therefore, nursing educators need to preferentially identify nursing students who are depressed, and such students should receive education about the importance of healthy beverage consumption habits to prevent repetitive energy drink consumption, in order to reduce the dependence of nursing college students on energy drinks.

The author hypothesized that self-esteem would affect the consumption of energy drinks in nursing students, based on existing literature on the close association between self-esteem and health behaviors in substance abusers [11]; however, in this study, we found no correlation between self-esteem and the stimulant beverage consumption habits of nursing college students. This may suggest that nursing students may not perceive energy drink consumption as an unhealthy beverage consumption habit, or that self-esteem may have little influence on the formation of healthy beverage consumption habits of healthy subjects without current health problems. Therefore, it may be necessary first to identify how nursing students perceive the effects of energy drink consumption on their health. Future research should investigate this issue by using qualitative research methods to analyze various factors that affect energy drink consumption among college nursing students.

More importantly, overconsumption of energy drinks, despite awareness of their adverse effects, is a major problem $[2,15]$. The existing literature suggests that it is necessary to regularly check levels of energy drink consumption among nursing students, to assess students for related mental health problems (especially focusing on depression), and to repeatedly educate students on proper energy drink consumption guidelines, while students are still learning about healthy behaviors in their nursing curriculum. These efforts may enable early detection and appropriate interventions for unhealthy dietary habits, so that the students can acquire knowledge about nursing while establishing healthy behaviors that can help improve both their own and others' health.

The limitations and suggestions of this study are as follows. The first limitation of this study was that the data were collected from students at a single nursing college in Korea. Thus, the interpretability of these results is limited to nursing students at that institution. For this reason, an expanded study should be conducted to investigate more nursing college students. The second limitation is that the consumption of energy drinks was analyzed categorically by dividing students into never-consumers and ever-consumers. It was therefore not possible to identify the psychological factors that affect the frequency and quantity of energy drink consumption among ever-consumers. For this reason, the author proposes further studies to characterize psychological influences on the frequency and quantity of energy drink consumption among ever-consumers. The third limitation is that the study focused 
only on psychosocial factors related to energy drink consumption and could not confirm potential associations with other factors. The author therefore suggests that further studies should seek to identify other associated socio-demographic factors or physical factors, such as sleep, that can affect or be affected by energy drink consumption.

\section{CONCLUSION}

Korean nursing students exhibited a high level of energy drink consumption. Those who were depressed were more likely to have consumed energy drinks over their lifetime than their non-depressed counterparts. Nursing educators should be aware of the psychological factors associated with energy drink consumption and should attempt to detect nursing students who experience psychological problems (e.g. depression) as early as possible. Furthermore, nursing educators should also strive to provide adequate, and early, education to correct unhealthy dietary habits among nursing students. These efforts will help establish healthy behaviors, thereby encouraging students to improve their own health, as well as the health of others. Furthermore, these results may be used to establish health behavior interventions for 3-shift health care workers.

\section{Conflict of interest}

No existing or potential conflicts of interest relevant to this article are reported.

\section{REFERENCES}

1. Ali F, Rehman H, Babayan Z, Stapleton D, Joshi DD. Energy drinks and their adverse health effects: A systematic review of the current evidence. Postgraduate Medicine. 2015;127(3):308-322. https://doi.org/10.1080/00325481.2015.1001712

2. Peacock A, Droste N, Pennay A, Miller P, Lubman DI, Bruno R. Awareness of energy drink intake guidelines and associated consumption practices: A cross-sectional study. BMC Public Health. 2016;16:6. https://doi.org/10.1186/s12889-015-2685-2

3. Lee HJ. Energy drink market triple storm growth. Kyunghyang Shinmun [Internet]. 2013 Jan 24 [cited 2018 Aug 24]; Market Biz. Available from:

http://biz.khan.co.kr/khan_art_view.html?artid=2013012408254 41\& code $=920100$.

4. Noh JD. "A tired society, a bottle up"... 2 trillion won functional beverage, ramen noodle market. Korea Economy [Internet]. 2016 Aug 3 [cited 2018 Aug 24]; Industry. Available from: http://www.hankyung.com/news/app/newsview.php?aid=201 6080365551.
5. Koo HJ. Work longer, work more... Drink instead of rest. Huffpost [Internet]. 2017 Feb 28 [cited 2018 Aug 24]; Lifestyle. Available from:

http://www.huffingtonpost.kr/salimstory/story_b_15053978.html.

6. Yum KH. 'Extreme job hunting stress' increases college student study time. iMBC news [Internet]. 2016 May 21 [cited 2018 Aug 24]; Evening news. Available from:

http://imnews.imbc.com/replay/2016/nw1800/article/3959500 _19830.html.

7. Attipoe S, Leggit J, Deuster PA. Caffeine content in popular energy drinks and energy shots. Military Medicine. 2016;181(9):1016-1020. https://doi.org/10.7205/MILMED-D-15-00459

8. Poulos NS, Pasch KE. Energy drink consumption is associated with unhealthy dietary behaviours among college youth. Perspectives in Public Health. 2015;135(6):316-321. https://doi.org/10.1177/1757913914565388

9. Richards G, Smith AP. A review of energy drinks and mental health, with a focus on stress, anxiety, and depression. Journal of Caffeine Research. 2016;6(2):49-63. https://doi.org/10.1089/jcr.2015.0033

10. Trapp GS, Allen K, O'Sullivan TA, Robinson M, Jacoby P, Oddy $\mathrm{WH}$. Energy drink consumption is associated with anxiety in Australian young adult males. Depression and Anxiety. 2014;31(5): 420-428. https://doi.org/10.1002/da.22175

11. Bitancourt T, Tissot MC, Fidalgo TM, Galduroz JC, da Silveira Filho DX. Factors associated with illicit drugs' lifetime and frequent/heavy use among students results from a population survey. Psychiatry Research. 2016;237:290-295. https://doi.org/10.1016/j.psychres.2016.01.026

12. Lee C, Dickson DA, Conley CS, Holmbeck GN. A closer look at self-esteem, perceived social support, and coping strategy: A prospective study of depressive symptomatology across the transition to college. Journal of Social and Clinical Psychology. 2014;33(6): 560-585. https://doi.org/10.1521/jscp.2014.33.6.560

13. Rath M. Energy drinks: What is all the hype? The dangers of energy drink consumption. Journal of the American Academy of Nurse Practitioners. 2012;24(2):70-76.

https://doi.org/10.1111/j.1745-7599.2011.00689.x

14. Kim IK, Kim KM. Energy drink consumption patterns and associated factors among nursing students: A descriptive survey study. Journal of Addictions Nursing. 2015;26(1):24-31. https://doi.org/10.1097/JAN.0000000000000061

15. Park JS, Lee EJ, Lee CY, Jung HS. Consumption status, risk awareness and experience of adverse effects of high-caffeine energy drink among university students. Journal of Korean Public Health Nursing. 2015;29(1):102-114. https://doi.org/10.5932/JKPHN.2015.29.1.102

16. Park S, Lee $Y$, Lee JH. Association between energy drink intake, sleep, stress, and suicidality in Korean adolescents: Energy drink use in isolation or in combination with junk food consumption. 
Nutrition Journal. 2016;15(1):87.

https://doi.org/10.1186/s12937-016-0204-7

17. Rodriguez-Gazquez M, Chaparro-Hernandez S, Gonzalez-Lopez JR. Are first-year nursing students' lifestyles coherent with their future career? International Journal of Nursing Practice. 2017;23 (2). https://doi.org/10.1111/ijn.12511

18. Kardakis T, Weinehall L, Jerden L, Nystrom ME, Johansson H. Lifestyle interventions in primary health care: Professional and organizational challenges. European journal of public health. 2014; 24(1):79-84. https://doi.org/10.1093/eurpub/ckt052

19. Rosenberg M. Society and the adolescent self-image. 1st ed. Princeton, NJ: Princeton University Press; 1965. p. 305-320.

20. Ryu Y. The effects of biblotherapy on self-esteem, character strengths, emotional awareness, and empathy in nursing students [dissertation]. Seoul: Seoul National University; 2015. p. 1-112.

21. Beck AT. Depression: Clinical, experimental, and theoretical aspects. 1st ed. Philadelphia, PA: University of Pennsylvania Press; 1967 p. 340-355.

22. Lee YH, Song JY. A study of the reliability and the validity of the BDI, SDS, and MMPI-D scales. The Korean Journal of Clinical Psychology. 1991;10(1):98-113.

23. Baker RW, Siryk B. Measuring adjustment to college. Journal of Counseling Psychology. 1984;31(2):179-189. https://doi.org/10.1037/0022-0167.31.2.179

24. Choi J, Park MJ. Methodological triangulation method to evaluate adjustment to college life in associate nursing college students. The Journal of the Korea Contents Association. 2013;13(7):339-349. https://doi.org/10.5392/JKCA.2013.13.07.339
25. Friis K, Lyng JI, Lasgaard M, Larsen FB. Energy drink consumption and the relation to socio-demographic factors and health behaviour among young adults in Denmark. A population-based study. European Journal of Public Health. 2014;24(5):840-844. https://doi.org/10.1093/eurpub/cku003

26. Reid JL, McCrory C, White CM, Martineau C, Vanderkooy P, Fenton $\mathrm{N}$, et al. Consumption of caffeinated energy drinks among youth and young adults in Canada. Preventive Medicine Reports. 2017;5:65-70. https://doi.org/10.1016/j.pmedr.2016.11.012

27. Attila S, Cakir B. Energy-drink consumption in college students and associated factors. Nutrition. 2011;27(3):316-22. https://doi.org/10.1016/j.nut.2010.02.008

28. Marczinski CA, Fillmore MT, Henges AL, Ramsey MA, Young CR. Mixing an energy drink with an alcoholic beverage increases motivation for more alcohol in college students. Alcoholism, Clinical and Experimental Research. 2013;37(2):276-83. https://doi.org/10.1111/j.1530-0277.2012.01868.x

29. Droste N, Tonner L, Zinkiewicz L, Pennay A, Lubman DI, Miller P. Combined alcohol and energy drink use: Motivations as predictors of consumption patterns, risk of alcohol dependence, and experience of injury and aggression. Alcoholism, Clinical and Experimental Research. 2014;38(7):2087-2095. https://doi.org/10.1111/acer.12438

30. Hofmeister EH, Muilenburg JL, Kogan L, Elrod SM. Over-thecounter stimulant, depressant, and nootropic use by veterinary students. Journal of Veterinary Medical Education. 2010;37(4):403416. https://doi.org/10.3138/jvme.37.4.403 